\title{
CHARACTERIZATION AND BENEFICIATION OF ANKA CHROMITE ORE USING MAGNETIC SEPARATION PROCESS
}

\author{
O.K. Abubakre ${ }^{1}$, R.A. Muriana ${ }^{2}$ and P.N. Nwokike ${ }^{3}$ \\ Mechanical Engineering Department, Federal University of Technology, Minna \\ 1.diranabubakre@yahoo.com, 2- mraremu@yahoo.com, 3 - Deceased
}

\begin{abstract}
Chromium is largely used as alloying elements in steels for production of stainless steels. It is added in form of ferro-chromium, which is presently imported from Russia and Germany to meet the need of Nigerian Steel Industry. Chromite ore $\left(\mathrm{FeOCr}_{2} \mathrm{O}_{3}\right)$ is the most important mineral occurrence of chromium, and some deposits are reported in Anka Local Government Area of Zamfara State. This work involves the analysis of collected ore samples from Anka in Zamfara State. The samples assaying 36.84\% of $\mathrm{Cr}_{2} \mathrm{O}_{3}$ was subjected to beneficiation process in order to enrich the ore, in terms of the $\mathrm{Cr}_{2} \mathrm{O}_{3}$, using magnetic separation. The results obtained after the analysis of the beneficiated ore using wet chemical analysis and Atomic Absorption Spectrometer shows that $\mathrm{Cr}_{2} \mathrm{O}_{3}$ content increased to $48 \%$ with a maximum Cr:Fe ratio of 6.2:1. The content of $\mathrm{Cr}_{2} \mathrm{O}_{3}$ is high enough and can be used for ferro-chromium alloy production.
\end{abstract}

Keywords: Ferro-alloys, Chromium recovery, Chromium Iron Ratio, Alloy steel, Atomic Absorption Spectrometer.

\subsection{INTRODUCTION}

Ferro-alloys are alloys of iron as the base metal and other leading alloying elements such as Silicon ( $\mathrm{Si}$ ), Manganese (Mn), Tungsten (W), Vanadium (V), and Chromium $(\mathrm{Cr})$. They are mainly used as additives in steel making processes and many other refining processes. Based on the quality of steels desired, the following ferro-alloys are commonly used in the production of iron and steels in melting shops: Ferro-silicon (Fe-Si), Ferro-manganese (Fe-Mn), Ferro-Tungsten (Fe-W), Ferro-chromium (Fe-Cr); Ferro-vanadium (Fe-V). The use of ferro-alloys in steel making is very important because of their effect on the quality of steels in terms of physical and mechanical properties and other alloying effects such as deoxidation capability, desulphurisation and dephosphorisation potentials [1] 
In Nigeria, the demand for ferro-alloy is expected to be on increase annually following the country's emphasis on accelerated industrialization hinged on fast growth in iron and steel industries. At the peak of capacity utilization of Aladja Steel Company, the annual demand for the various grades of ferro-alloys is about 15,000 tones per annum. [2]. The prospect of rapid increase in the demand for ferro-alloys is envisaged with the success of the current reforms of present regime aimed at attracting investors with technical expertise, managerial skill and resources to turn the public Iron and Steel plants around. This couple with the emphasis of the present regime on the development of the solid minerals in the country has made investigation into the locally available sources of chromite ore and other ferro-alloys inevitable [3 and 4].

This present work is aimed at investigating the quality, metallurgical and general engineering properties of locally sourced chromite ore from Tunga Kuduka, Anka Local Government Area of Zamfara State. Chemical analysis of the ore was carried out and various ore processing techniques such as mineralogical studies, ore dressing, particles size analysis was employed. The beneficiation of the ore was carried out using magnetic separation technique. The results obtained after the chemical analysis of the beneficiated ore using Atomic Absorption Spectrometer shows that $\mathrm{Cr}_{2} \mathrm{O}_{3}$ content increased to $48 \%$ with maximum $\mathrm{Cr}$ :Fe ratio of 6.2:1. The content of $\mathrm{Cr}_{2} \mathrm{O}_{3}$ is high enough and can be used for ferro-chromium alloy production.

\subsection{LITERATURE REVIEW}

Minerals are natural inorganic substances possessing definite chemical compositions and atomic structures. An ore is described generally as an accumulation of mineral in sufficient quantity as to be capable of economic extraction. The minimum metal content required for a deposit to qualify as an ore varies from metal to metal while the suitability of a deposit for economic mining and processing is controlled by location and size of the deposit, the ore-feed grade, mineralogy, and texture of the ore, mining cost and the cost of ancillary services such as power -supply, water, roads, tailings disposal and amenability of the ore to economically viable treatment and the demand for and value of the metal and its concentrates [5].

\subsection{Chromium in Steel Industry}

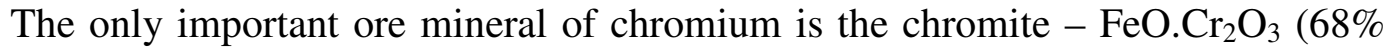
$\mathrm{Cr}_{2} \mathrm{O}_{3}, 32 \% \mathrm{FeO}$ ) which crystallizes in the isometric system. The hardness value is 5.5 on Mohr scale and its specific gravity is 4.6. In colour, it is iron - black to brownish -black. Pure chromite with composition $\mathrm{FeCr}_{2} \mathrm{O}_{4}$ is rare because magnesium usually substitutes for some ferrous ion and aluminum and ferrous ion substitutes for chromium.

Chromium is produced in the form of ferro-chromium by various methods ranging from reduction in an electric furnace, electrolysis, thermal dissociation, thermal decomposition. Ferro-chromium has been produced by reduction of chromite ores with carbon or silicon in an electric furnace. It can also be produced by a silicon thermic 
reaction in the presence of suitable oxidizing agents such as calcium chromate $\mathrm{CaCrO}_{4}$, sodium nitrate $\mathrm{NaNO}_{3}$, or manganese dioxide $\mathrm{MnO}_{2}$ in an exothermic reaction. It can equally be produced by exothermic reduction of chemically produced $\mathrm{Cr}_{2} \mathrm{O}_{3}$ using powdered aluminum as the reductant. The use of aluminum is associated with explosive hazards and with considerable losses of chromium while molten aluminum in an arc furnace at $1493^{\circ} \mathrm{C}$ reacts vigorously with $\mathrm{Cr}_{2} \mathrm{O}_{3}$. To avoid this explosion the molten aluminum is best poured at a lower temperature into a melt of $\mathrm{Cr}_{2} \mathrm{O}_{3}$ and with vigorous stirring, nearly $94 \%$ of chromium recovery has been reported.

Chromium metal is also produced on a commercial scale by electrolysis of an ammonium chromium alum solution prepared either from chromium ore or from high carbon ferro-chromium. In addition it is produced in more limited quantities by thermal dissociation of chromium iodide in contact with a suitable heated deposition surface under vacuum conditions. This gives the purest chromium presently available [6].

\subsection{Beneficiating Chromite Ore}

Beneficiation operations typically serve to separate and concentrate mineral values from waste materials, remove the impurities or prepare the ore for further refinement. Beneficiation activities do not change the mineral values themselves other than by reducing (crushing and grinding) or enlarging (pelletising and briquetting) particle size to facilitate further processes.[7]. Chromite ore is beneficiated for processing using several methods, depending on the ore source and the end use requirements. Coarse clean ore is hand sorted, while the fine clean ore is gravity separated. Lumpy ore mixed with host rock may require heavy medium separation. If chromite minerals occurs in fine grains intermixed with host rock, crushing, gravity separation and magnetic separation may be used [8].

Various approaches have been used by different researchers to upgrade chromite ores. Thermal beneficiation was successfully carried out on a low grade chrome ore from Vagda deposits, Ralnagiri District, Maharashtra India. The method employed was preferential roasting reduction and acid - leaching. The initial chromium - iron ratio of $1.53: 1$ was increased by this approach to $8: 1$ with more than $87 \%$ chromium recovery. The preferentially reduced ore from 72 mesh to 170 mesh (B. S. S) was roasted at $1250^{\circ} \mathrm{C}$ for a period of two and a half hours with subsequent leaching with dilute tetraoxosulphate (VI) acid. The effect of temperature on reduction was investigated within the range $1,100^{\circ} \mathrm{C}$ to $1,300^{\circ} \mathrm{C}$. It was observed that the percentage of ore reduced and dissolved on leaching sharply increased from $22.84 \%$ to $80.78 \%$ at $1,200^{\circ} \mathrm{C}$ and with no improvement noticed at higher temperature. (Ives, 1972). Beneficiation of chromite ore using selective chlorination was successfully employed to improve the low grade ore in South Africa. The Cr:Fe ratio attained, using this approach was 20:1 [9]

\subsection{Magnetic Separation Technique}

Magnetic separation process exploits the difference in magnetic properties between the ore minerals and is employed to separate valuable mineral from nonmagnetic gangues. All materials are affected in some way when placed in a magnetic 
field, though with most substances, the effect is too slight to be detected. Materials are classified into paramagnetic and diamagnetic depending whether or not the effect of magnetic field on them are strong respectively.

The magnetizing force which induces the lines of force through a material is called the field intensity. The capacity of a magnet to lift a particular mineral is dependent not only on the value of the field intensity, but also on the field gradient, which is the rate at which the field intensity increases towards the magnet surface.

$$
\begin{aligned}
& F \propto H \frac{d H}{d t} ;---------2.1 \\
& F=\mu_{o} H \frac{d H}{d t}--------2.2
\end{aligned}
$$

where $\mathrm{F}$ is the force on the particle, $\mathrm{H}$ is the field intensity, and $\mathrm{dH} / \mathrm{dt}$ is the field gradient Thus in order to generate a given lifting force, there are an infinite number of combinations of field and gradient which will give the same effect. Production of a high field gradient as well as high intensity is therefore an important aspect of separator design.

\subsection{EXPERIMENTAL PROCEDURES}

\subsection{Size Analysis}

A sample of the ore was crushed and ground to fine particle size ranges and subjected to sieve analysis. At the end of five minutes, the nest was taken apart the amount of material retained on each sieve was weighed. The result of the sieve analysis of the sample was recorded.

\subsection{Chemical Analysis of the Anka Chromite Ore for Chromium: Iron Ratio}

The size fractions obtained from the particle size analysis were subjected to chemical analysis. Weighed amounts of the chrome ore concentrate and coke were briquetted with $1 \%$ dextrine in the presence of $2 \%$ moisture under a pressure of 5.0 PSI. The coke sample used for the investigation contained $75.52 \%$ fixed carbon, $22.51 \%$ ash and $1.95 \%$ volatiles.

The dried briquettes were placed in a tightly covered crucible and heated at a desired temperature for a specific period in a crucible furnace. The briquettes were cooled under cover after reduction and crushed to pass through the size ranges used for sieve analysis. A weighed amount of the reduced ore powder was then leached with excess of $10 \%$ by volume tetraoxosulphate (vi) acid solution under boiling condition for an hour. The slurry was then filtered and the residue free from acid. The leach cake was air dried at $110^{\circ} \mathrm{C}$ and the $\mathrm{Fe}: \mathrm{Cr}$ ratios was calculated using leach liquor analysis and weight loss after reduction. 


\subsection{Wet Chemical Analysis}

Standard chemical procedure [10] was employed to determine total iron content and contents of Silica $\left(\mathrm{SiO}_{2}\right)$, Alumina $\left(\mathrm{Al}_{2} \mathrm{O}_{3}\right)$, Calcium Oxide $(\mathrm{CaO})$ and Magnesium Oxide $(\mathrm{MgO})$ in the sample.

\subsection{Magnetic Separation of Anka Chromite Ore}

In this operation, use was made of the cross-belt separator. This technique is a continuous process carried out on a moving stream of particles passing into and through magnetic field. In this technique close control of the velocity of the passage of the particles is ensured to drastically reduce the chances of free-fall. The dry material was fed in a uniform layer on to the conveyor belt and was carried between the poles of the magnetic system, which consists of two or more horse-shoe electromagnets, the poles being arranged one above the other. This arrangement ensures the concentration of the force fields which then attract the paramagnetic materials towards the poles. The crossbelt serves to prevent the magnetic particles from adhering to the poles and carry them out of the field.

For this work, two kilograms $(2 \mathrm{~kg})$ of the ore was used and at the end of the operation, the magnetic material obtained weighed $739.94 \mathrm{~g}$ representing $36.997 \%$ while the balance weighed $1260.06 \mathrm{~g}$ representing $63.003 \%$ of the total material. The wet chemical analysis of the concentrate was also carried out.

The concentrate was pulverized and size fractions 72,100,120,170,200, and 250 BSS mesh were subjected to the Atomic Absorption spectroscopy and the result for percentage chromium recovery and $\mathrm{Cr}$ :Fe ratios obtained is presented in Figure 2 while the result of the analysis of the concentrate is shown in Table 2.

\subsection{RESULT AND DISCUSSIONS}

The result of the chemical analysis study of the Anka chromite ore using wet chemical analysis is presented in the Table 1. From the result shown in the table it is seen that the Anka deposit is rich in Chromium assaying $36.84 \% \mathrm{Cr}_{2} \mathrm{O}_{3}$, It also shows that other compounds such as $\mathrm{FeO}, \mathrm{MgO}, \mathrm{Al}_{2} \mathrm{O}_{3}, \mathrm{SiO}_{2}$ and $\mathrm{CaO}$, which are of industrial values, are in association.

The ore could be classified to be of medium grade when compared with other worlds deposits such as the Turkish ore (Gostar and Vagda deposits) containing 30\% $\mathrm{Cr}_{2} \mathrm{O}_{3}$, Ratnagiri District Maharashtra which contains $33.14 \% \mathrm{Cr}_{2} \mathrm{O}_{3}$, and Central Ural deposits in Russia containing $30-39 \% \mathrm{Cr}_{2} \mathrm{O}_{3}$ [6 and 11].

The result of the sieve analysis of the ore sample is presented in the Fig 1 . The coarse component of the ore is quite significant. More than $50 \%$ weight falls within sieve aperture size of $1000-500 \mu \mathrm{m}$. The proportion of the extremely fine particles is also considerable constituting about $10 \%$ weight of the sample.

The variation in percentage chromium recovery and the change in $\mathrm{Fe}: \mathrm{Cr}$ ratio at different mesh size is presented in Figure 2. The result shows that $\mathrm{Cr}$ :Fe ratio appreciated progressively above particle of mesh size of 100 and falls again as the particles become finer. The fall in Chromium: Iron ratio can be attributed to losses of the valuable minerals 
as the fineness of the particle increases. An average sample of the enriched ore taken from mesh sizes ranging between 70 - 250 BSS were subjected to both wet chemical analysis and Atomic Absorption Spectroscopy and results are as shown in Table 2.

The results in the table shows again that the maximum chromium recovery lies in the size ranges considered as any progress on either side of the size ranges results to a noticeable drop in chromium recovery.

Table 1: Chemical Analysis of raw sample of Anka Chromite Ore

\begin{tabular}{|l|l|l|l|l|l|l|l|}
\hline Molecules & $\mathrm{FeO}$ & $\mathrm{MgO}$ & $\mathrm{Cr}_{2} \mathrm{O}_{3}$ & $\mathrm{Al}_{2} \mathrm{O}_{3}$ & $\mathrm{SiO}_{2}$ & $\mathrm{CaO}$ & Others \\
\hline Composition \% & 21.51 & 14.00 & 36.84 & 11.00 & 13.74 & 2.24 & 0.67 \\
\hline
\end{tabular}

Table 2: Chemical Composition of the Enriched Ore

\begin{tabular}{|l|l|l|l|l|l|l|l|}
\hline Compound & $\mathrm{FeO}$ & $\mathrm{MgO}$ & $\mathrm{Cr}_{2} \mathrm{O}_{3}$ & $\mathrm{Al}_{2} \mathrm{O}_{3}$ & $\mathrm{SiO}_{2}$ & $\mathrm{CaO}$ & Others \\
\hline Analysis based on AAS & 13.80 & 10.00 & 44.68 & 16.76 & 2.46 & 1.34 & 10.96 \\
\hline Wet Chemical Analysis & 11.57 & 11.35 & 43.97 & 16.38 & 3.56 & 2.21 & 10.96 \\
\hline
\end{tabular}

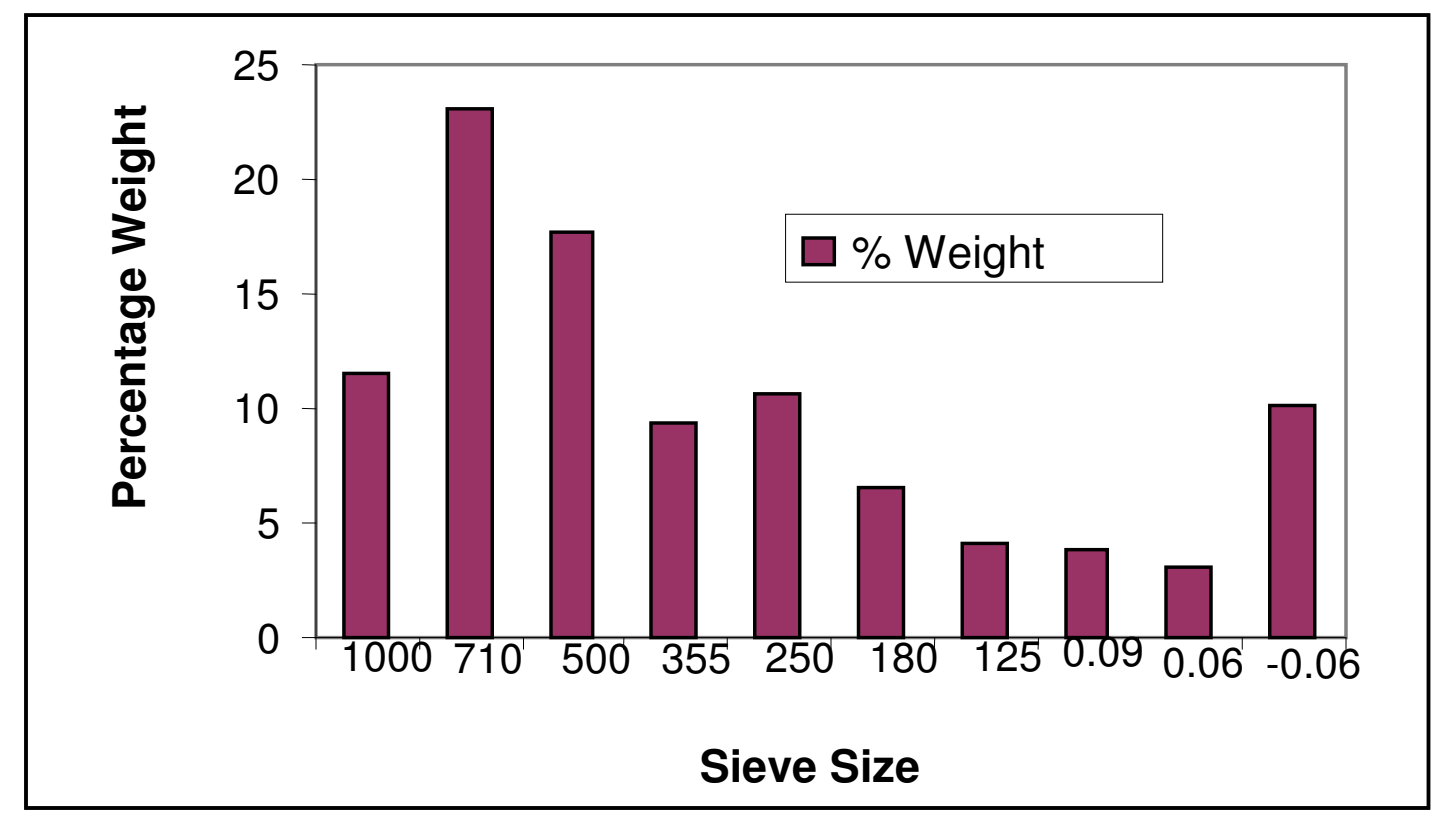

Figure 1: Result of Sieve Analysis of the Chromite Ore Sample. 


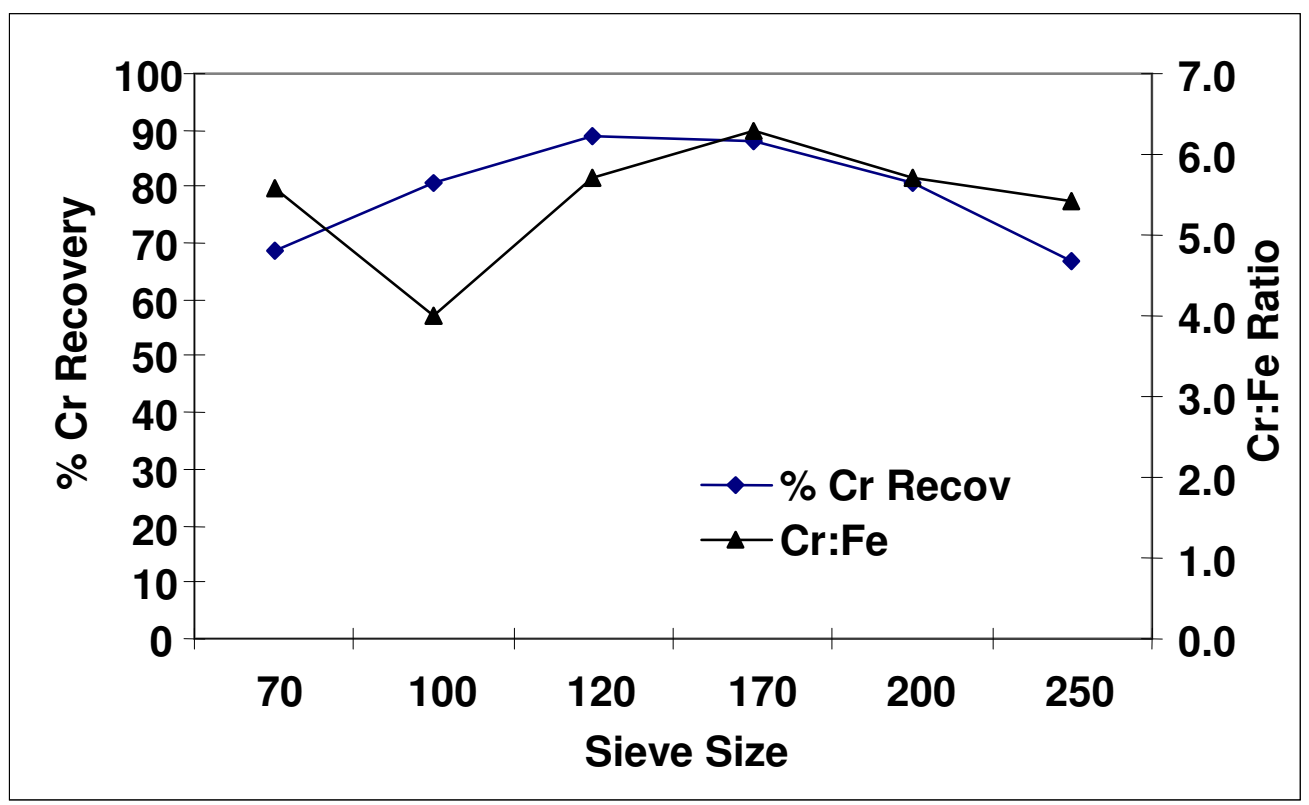

Figure 2: Variation of Chromium Recovery and Cr:Fe ratio with particle size.

\subsection{Conclusion}

Magnetic separation is known to be more appropriate for treating fine particles. However, the greater tendency of the associated gangue materials to form dust more readily than chromite ore may be responsible for poor chromium recovery as the fineness of Anka chromite deposit increases.

The characterized ore was successfully upgraded to meet specification for metallurgical use by conventional ore dressing methods.

It was also established that chromium ore can best be beneficiated for maximum chromium recovery in fraction ranges $100-200$ mesh (BSS).

\section{References}

1. Kudrin V.A. (1988) "Steel Making” Mir Publisher. Moscow. P.358

2. Ubokwe and Khan (1996) Processing and Beneficiation of Quarzite, Manganese and Chromite Ores for ferro-alloy production in Nigeria. Nat. Engg. Conf. Bauchi, April, 1996."

3. Siyan Malomo (2003) "Materials for the Mineral Industry and the Challenges of Processing” Annual Conference of Nigerian Materials Society (MRS), Akure. 
4. Yaro S.A (2004) "Upgrading of Muro-Toto iron ore gravity pre-concentrate by Reverse Froth Floatation Method" Journal of Raw Materials Research, Vol 1 No 1, 2004 pp 54-59.

5. Wills B.A. (1989), Mineral Processing Technology $3^{\text {rd }}$ Edition Pergamon. New York. 6. Gasik M.I., Likichev N.P. and Emlin B.I. (1988) "Theory and Technology of Ferroalloy Production" Metallurgy Publisher, Moscow p. 784.

7. "Chromium and Chromium Alloys" in Kirk-Othmer Encyclopaedia of Chemical Technology, $4^{\text {th }}$ Edition, Vol VI, 1993 p. 230.

8. John Papp (1994) "Chromite" in Industrial Minerals and Rocks. $6^{\text {th }}$ Edition Society for Mining, Metallurgy and Exploration. P. 210

9. Robinson M, Wilson H.B., Crosby A.D, Talati K (1981)"Beneficiation of Chromite Ore and other ores by Selective Chlorination" Journal of Extraction Metallurgy, London Sept, 1981, pp 393 - 403.

10. Petruck, W. (1976) “The Application of Quantitative Mineralogical Analysis of Ores to predict the optimum Grind" Canadian Mineral Processors, Ottawa.

11. Nwokike P.N. (2003) "Characterization And Beneficiation Of Anka Chromite Ore" Draft M.Eng Thesis, FUT, Minna. 